\title{
Effect of Lemongrass Essential Oil as Aromatherapy Agent on Dental Anxiety in Children: A Cross-sectional Study
}

\author{
Jonnalagadda Radhalakshmi ${ }^{1}$, Aron AK Vasa ${ }^{2}$, Suzan Sahana ${ }^{3}$
}

\begin{abstract}
Introduction: Managing dental anxiety in children is one of the most difficult tasks for pediatric dental practitioners. Pure essence of essential oils has been shown to be useful in reducing dental anxiety in adults; this study is an attempt to see their effects on children.

Aim: To explore the effect of lemongrass oil in reducing dental anxiety in children.

Materials and methods: A total of 40 children, aged 8-11 years, attending for their first dental visit, were randomly divided into two groups. This comprised of control and experimental groups conditioned to exposure using a candle warmer with normal water and with lemongrass oil, respectively. Psychometric and objective assessment of anxiety was done using the "Venham's picture test" and "pulse oximeter" for both the groups. The pre- and postexposure scores were tabulated and the obtained data were analyzed using the paired $t$ test and analysis of variance (ANOVA).

Results: The postexposure mean scores of Venham's picture scale (VPS) and pulse rate were lower in the experimental group. This shows that the lemongrass oil produced significant reduction in anxiety among the subjects.

Conclusion: Aromatherapy using lemongrass oil can be recommended in routine pediatric dentistry practice as an effective means of reducing dental anxiety in children.

Keywords: Dental anxiety, Essential oil, Lemongrass oil aromatherapy.

CODS Journal of Dentistry (2018): 10.5005/jp-journals-10063-0043
\end{abstract}

\section{INTRODUCTION}

Children experience anxiety when they are away from a comfortable environment. Reception area at a dental office is one such location where children encounter apprehension as they are uncertain about the procedures they may be subjected to. Further, there is evidence to infer that children are more anxious than adults when they receive medical treatment and care. ${ }^{1}$

Anxiety is defined as a nonspecific feeling of apprehension, worry, uneasiness, or dread, the source of which may be vague or unknown. Dental anxiety has been defined as "abnormal fear or dread of visiting the dentist for preventive care or therapy and unwarranted anxiety over dental procedures." The various schools of psychological thought agree that anxiety is a personality trait, but they have various opinions concerning the origin of this trait. Several variables in children's backgrounds have been identified as stimuli related to it. Dental anxiety may even originate from lack of exposure to the dental environment at all. ${ }^{2}$

Managing dental anxiety in children is one of the most difficult tasks for pediatric dental practitioners. Numerous pharmacological and nonpharmacological means of behavior management are being employed in the routine dental practice with varying degrees of success. However, use of pharmacological means like conscious sedation or general anesthesia carries some risks and these procedures cannot be routinely applied to every patient undergoing dental treatment. ${ }^{3}$

Recently, contemporary and alternative medicine approaches have been considered for use in dental and medical settings. Aromatherapy is one such alternative medical approach that includes the inhaled, absorbed, or ingested use of essential oils for prophylactic treatment. This method is supporting the concept that common oils can produce the positive pharmacological and physiological effect by the sense of smell. It has been observed
${ }^{1-3}$ Department of Pedodontics and Preventive Dentistry, St. Joseph Dental College, Eluru, Andhra Pradesh, India

Corresponding Author: Aron AK Vasa, Department of Pedodontics and Preventive Dentistry, St. Joseph Dental College, Eluru, Andhra Pradesh, India, Phone: +91 9912014111, e-mail: vasaaron@gmail.com

How to cite this article: Radhalakshmi J, Vasa AAK, Sahana S. Effect of Lemongrass Essential Oil as Aromatherapy Agent on Dental Anxiety in Children: A Cross-sectional Study. CODS J Dent 2018;10(1):11-15.

Source of support: Nil

Conflict of interest: None

that the parasympathetic nervous system activity is increased by $12 \%$ and sympathetic activity is decreased by $16 \%$ with orange oil. Hence, aroma therapists supported the use of orange essential oil as a tranquilizer. ${ }^{4}$

Likewise, the effect of aromatherapy on dental anxiety has been assessed in few studies. Lavender scent, bergamot oil, and apple odors among others have been investigated mostly among the adult population. One study that investigated the effect of gender and ethnicity on preferences and attitudes in children reported that children are very different from adults in their odors and taste preferences. Hence, children are likely to accept essential oils that they find pleasant. ${ }^{4,5}$

Lemongrass, a culinary herb with medicinal properties, has a subtle citrus flavor. It is an aromatic storehouse of essential nutrients providing an array of health benefits. Lemongrass also consists of beneficial ingredients of essential oils such as neroli, citronellol, myrcene, dipentene, geraniol, and methyl heptenone. ${ }^{6}$

Given the potential effect of essential oils, the aim of the present study was to explore the effect of lemongrass oil on anxiety levels of children awaiting dental procedures in a dental office. 


\section{Materials and Methods}

A total of 40 children, aged 8-11 years, attending for their first dental visit were included as study participants. An informed consent was obtained from the children's guardians/parents prior to their participation. The study protocol was approved by the institutional ethical board (Ref no: CEC/19/2/2017-18).

\section{Eligibility Criteria}

- Children who have sound physical, psychological, and mental health.

- Children with no history of previous dental visit.

- Children with no history of allergies or other medical ailments. A simple random sampling method was employed to randomly divide study participants into two groups.

- Group I (control)—exposed to a candle warmer with normal water (Fig. 1).

- Group II (experimental) —exposed to a candle warmer with lemongrass oil (Fig. 2).

All participants who arrived for their first dental visit were asked to fill a questionnaire comprising demographic information and the purpose of dental visit. Psychometric assessment of dental anxiety was done based on the "Venham's picture test" (Fig. 3). Each child was asked to point out the figure that represents their state of mind the most. A score of 1 was recorded for each distressed figure selected by the patient and the scores are summed up. Thus, score can vary between 0 and 8 . Higher scores indicate high anxiety. ${ }^{2}$ The final score was interpreted as follows:

\begin{tabular}{ll}
\hline Score & Status \\
\hline 8 & Very high anxiety \\
$6-8$ & High anxiety \\
$4-6$ & Average \\
$2-4$ & Low anxiety \\
$0-2$ & Very low anxiety \\
0 & No anxiety \\
\hline
\end{tabular}

A pulse oximeter was used as a biological marker, to assess the "pulse rate" and "oxygen saturation" (Fig. 4). Then the patients

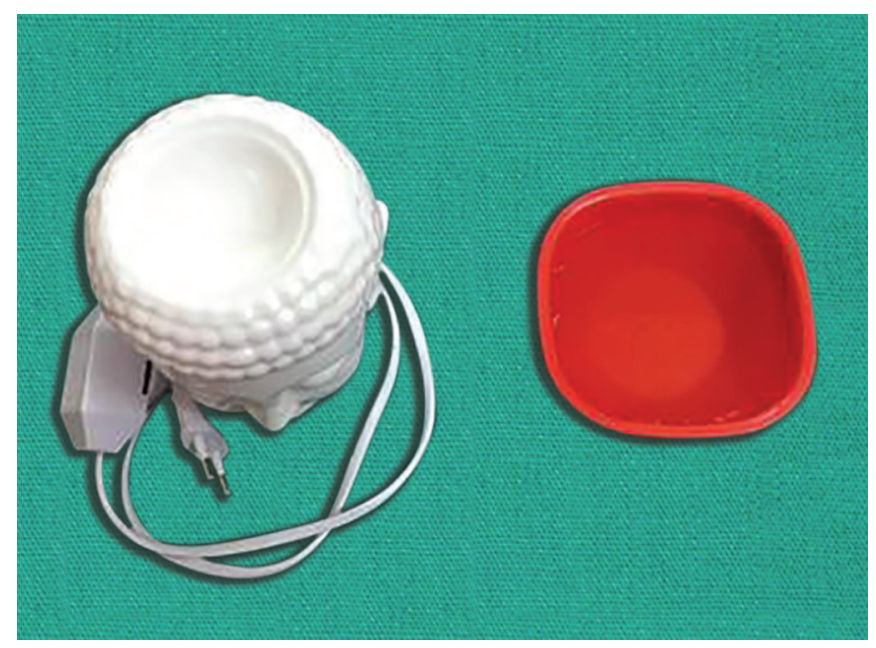

Fig. 1: Candle warmer with distilled water were instructed to be seated in the aromatherapy conditioning waiting room for 15 minutes and their favorite cartoon videos were played. In the experimental group, the candle warmer with essential oil (lemongrass) diluted with water in the ratio of 1:1 was placed and activated half an hour before the arrival of the first patient. In the control group, a candle warmer with normal water was used. Conditioning was done either with lemongrass oil or distilled water according to the group assigned (Fig. 5).

At the end of stipulated 15 minutes, the subjective and objective assessment of anxiety was repeated using the "Venham's picture test" and a pulse oximeter (Fig. 6).

The pre and postconditioning scores thus obtained were compared and statistically analyzed. The paired $t$ test for determining the difference between the anxiety scores and analysis of variance (ANOVA) for intergroup comparison was used. The level of significance was set at 0.05 .

\section{Results}

Forty children with the mean age of 9.2 years participated in the study. This included 37 male and 3 female children (Table 1).

The initial assessment of anxiety using the Venham's picture test showed similar scores for all the participants prior to conditioning. There was no statistical difference between the levels of anxiety between control and experimental groups. The postexposure assessment following conditioning in the waiting room showed statistical significant reduction in anxiety among the children in the experimental (lemongrass) group (Table 2).

Similarly, the mean baseline scores of the pulse rate showed similar values in both groups prior to conditioning. However, the postexposure scores were lower in the lemongrass oil group only, which was statistically significant (Table 3 ).

With respect to oxygen saturation, inter and intragroup comparisons showed no significant difference. Though the mean scores of the experimental and control group at pre- and postexposure states differed, it was not statistically significant (Table 4).

\section{Discussion}

Anxiety is considered a normal aspect of children's behavioral and emotional development. ${ }^{7}$ Owing to uncertainty, children

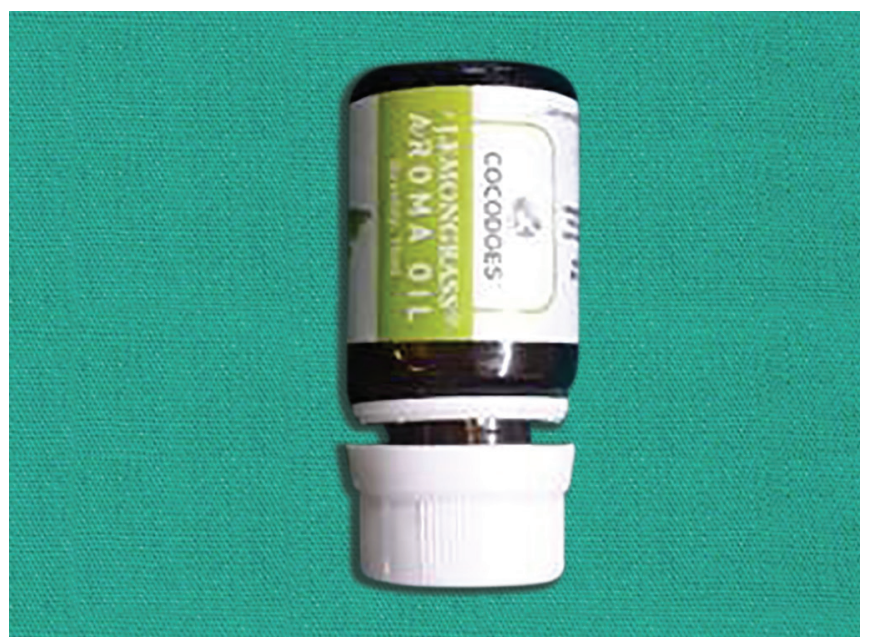

Fig. 2: Lemongrass oil 


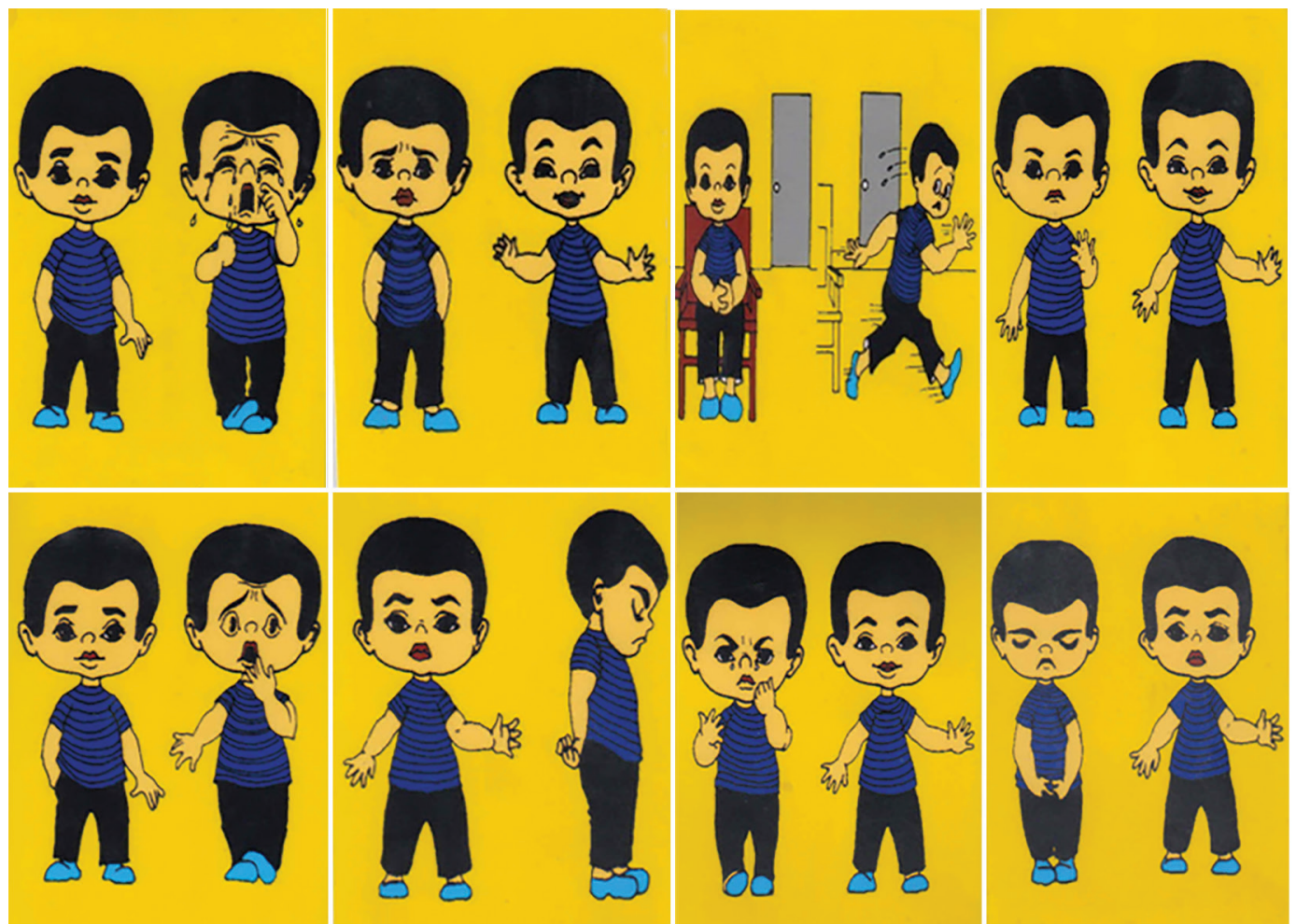

Fig. 3: Venham's picture test

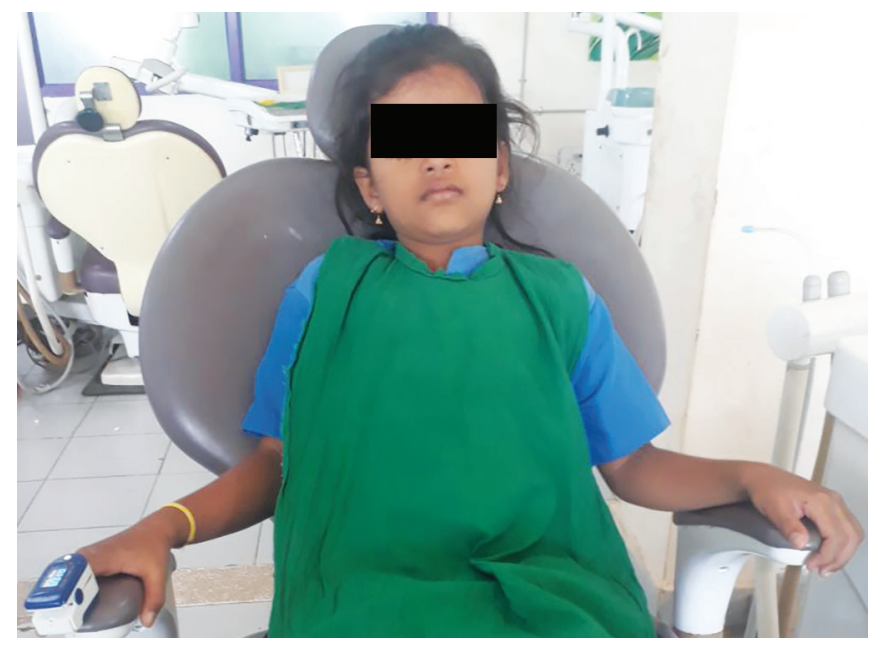

Fig. 4: Objective assessment of anxiety using pulse oximeter

experiencing first dental visit may have a nonspecific feeling of apprehension. The present study assessed the effects of aromatherapy using lemongrass essential oil as a strategy for anxiety management among children who had their first dental visit. Children in the age group of 8-11 years undergoing first dental visit were assessed as it may tend to produce significant anxiety compared to subsequent visits.

Aromatherapy is a treatment method that uses certain aroma stimuli media derived from certain aromatic plant oils, including essential oils and other aroma compounds. Previous studies have shown that aromatherapy can reduce a person's anxiety level. ${ }^{3}$ This study tested the effectiveness of lemongrass essential oil as it is known to possess beneficial and active ingredients.

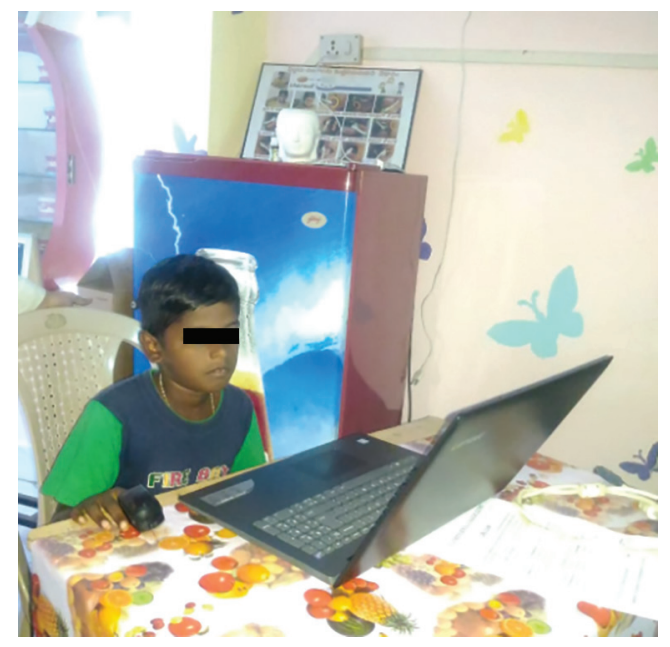

Fig. 5: Conditioning prior to dental treatment

Anxiety is an internal state that cannot be fully measured by an observer. It has been suggested that the most comprehensive assessment of anxiety should involve the use of a combination of behavioral, physiological, and self-report measurement techniques. ${ }^{1}$ A self-report measure employing pictures would serve better to young children. Hence, the present investigation employed a combination of psychometric test and biological markers for the assessment of anxiety. The Venham's picture test measures the state dental anxiety, which is easy to administer and score. It consists of eight cards with pictures of children in various dental situations. Each card has two figures, one in which a child appears happy and other one in which he/she looks distressed. Children would be asked how they feel about 
visiting the dentist, to point out the figure they liked the most and scored accordingly.

Stress and anxiety alter the respiratory rate and thereby alter oxygen saturation in the blood. ${ }^{8}$ Hence, pulse oximeter was also used to monitor the alterations.

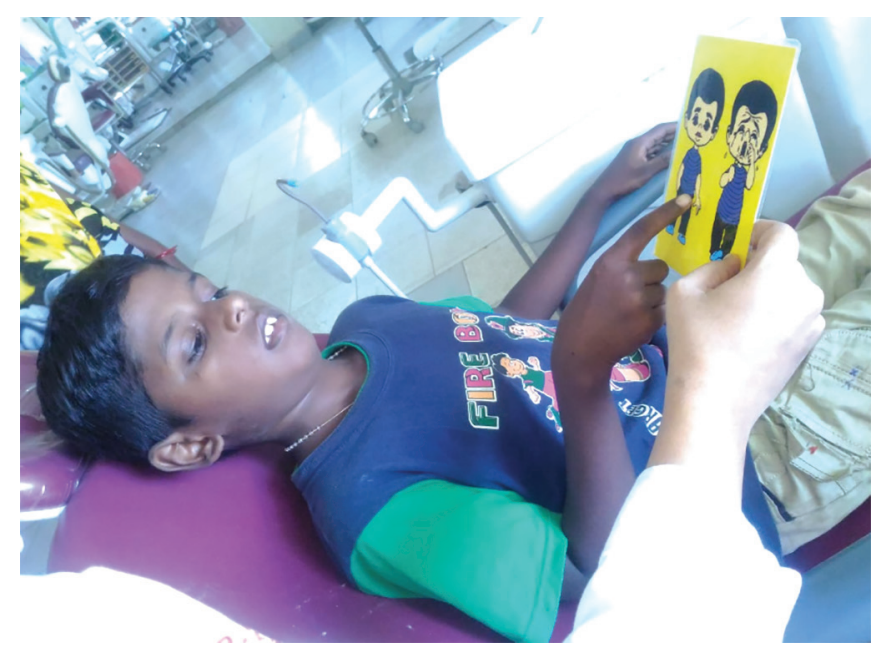

Fig. 6: Subjective assessment of anxiety using Venham's picture test

Table 1: Distribution of the sample

\begin{tabular}{lrl}
\hline Groups & Mean age (years) & Total \\
\hline Group I & $8.9 \pm 1.04$ & 20 \\
Group II & $9.95 \pm 1.24$ & 20 \\
Total & $5.2825 \pm 4.15$ & 40 \\
\hline
\end{tabular}

The results of this study revealed that the anxiety reduction effect due to lemongrass essential oil aromatherapy was significant compared to the anxiety level seen in the control group. This can be attributed to the fact that lemongrass essential oil contains neroli as the main component, which is extensively used in aromatherapy to relieve chronic depression. Inhaling the aroma of neroli essential oil is thought to transmit messages to the part of brain (limbic system) that controls emotions, which in turn influences the nervous system thereby causing stress alleviation and enhanced mood. ${ }^{9}$

On inhalation of scented oils, the volatile molecules bind to olfactory receptors, creating an electrophysiological response that reaches the brain. Neocortex activation is expected to occur by this response, which has an effect on perception of odors and reaches the limbic system including amygdale and hypothalamus, the areas where levels of hormone and emotions are controlled. ${ }^{4}$ Thus the pulse rate decreases following aromatherapy, which is evident in the present study.

The findings in the present study are in agreement with the results obtained by Jaafarzadeh et al. and Pradopo et al. with the use of orange essential oil and pandan leaves aromatherapy, respectively, to reduce dental anxiety in pediatric patients. ${ }^{4,10}$

Audiovisual aids are considered to be able to stimulate the brain that brings about a relaxing effect. It has also been reported in a study that the highest anxiety reduction occurred in patients with a combination of aromatherapy and relaxation music. ${ }^{10}$ Therefore, in adjunct to aromatherapy, during the waiting period in the conditioning room, all participants were allowed to watch their favorite cartoon videos. However, in the present investigation, watching their favorite video did not have any additive effect as the anxiety reduction was not significant among control group participants.

Table 2: Means of Venham's picture scale preexposure and postexposure in experimental and control groups

\begin{tabular}{llllll}
\hline & & \multicolumn{4}{c}{ VPS } \\
\cline { 3 - 6 } & & $n$ & Mean & Std. deviation & $p$ \\
\hline Experimental group & Preexposure & 20 & 0.70 & 1.867 & 0.15 (significance) \\
& Postexposure & 20 & 0.25 & 0.123 & \\
Control group & Preexposure & 20 & 1.8 & 3.222 & 0.367 (no significance) \\
& Postexposure & 20 & 2.30 & 3.496 & \\
\hline
\end{tabular}

Table 3: Means of pulse rate preexposure and postexposure in experimental and control groups

\begin{tabular}{|c|c|c|c|c|c|}
\hline & & \multicolumn{4}{|c|}{ Pulse rate } \\
\hline & & $n$ & Mean & Std. deviation & $p$ \\
\hline \multirow[t]{2}{*}{ Experimental group } & Preexposure & 20 & 98.10 & 7.398 & 0.002 (significance) \\
\hline & Postexposure & 20 & 91.70 & 8.405 & \\
\hline \multirow[t]{2}{*}{ Control group } & Preexposure & 20 & 105.60 & 12.504 & 0.173 (no significance) \\
\hline & Postexposure & 20 & 100.35 & 11.490 & \\
\hline
\end{tabular}

Table 4: Means of oxygen saturation preexposure and postexposure in experimental and control groups

\begin{tabular}{|c|c|c|c|c|c|}
\hline & & \multicolumn{4}{|c|}{ Oxygen saturation } \\
\hline & & $n$ & Mean & Std. deviation & $p$ \\
\hline \multirow[t]{2}{*}{ Experimental group } & Preexposure & 20 & 97.50 & 4.583 & 0.201 (no significance) \\
\hline & Postexposure & 20 & 95.35 & 6.923 & \\
\hline \multirow[t]{2}{*}{ Control group } & Preexposure & 20 & 97.75 & 4.011 & 0.345 (no significance) \\
\hline & Postexposure & 20 & 95.10 & 11.805 & \\
\hline
\end{tabular}




\section{Conclusion}

- Fragrance of lemongrass oil is an effective means of reducing dental anxiety in children.

- The use of aromatherapy can hence be recommended in routine pediatric dentistry practice in order to improve the quality of dental treatments.

Although this study provides evidence in favor of the use of lemongrass essential oil in dental settings for the management dental anxiety, future research is recommended to be carried out with larger sample size and in children of lower age range.

\section{References}

1. Cardinal FG, Arroyo GM, Magbanua SH, et al. Measurement of anxiety in 3-9 years old children receiving nursing intervention. J Caring Sci 2017;6(4):293-302. DOI: 10.15171/jcs.2017.028.

2. Agarwal M, Das UM. Dental anxiety prediction using Venham picture test: a preliminary cross-sectional study. J Indian Soc Pedod Prev Dent 2013;31(1):22-24. DOI: 10.4103/0970-4388.112397.

3. Zabirunnisa MD, Gadagi JS, Gadde P, et al. Dental patient anxiety: possible deal with lavender fragrance. J Res Pharm Pract 2014;3(3):100-103. DOI: 10.4103/2279-042X.141116.
4. Jaafarzadeh M, Arman S, Pour FF. Effect of aromatherapy with orange essential oil on salivary cortisol and pulse rate in children during dental treatment: a randomised controlled clinical trial. Adv Biomed Res 2013;2(1):1-7. DOI: 10.4103/2277-9175.107959.

5. Lehrner J, Marwinski G, Lehr B, et al. Ambient odors of orange and lavender reduce anxiety and improve mood in a dental office. Physiol Behav 2005;86(1-2):92-95. DOI: 10.1016/j.physbeh.2005.06.031.

6. Leite JR, Seabra Mde L, Maluf E, et al. Pharmacology of lemongrass (Cymbopogon citratus stapf) III. Assessment of eventual toxic, hypnotic and anxiolytic effects on humans. J Ethnopharmacol 1986;17(1):75-83. DOI: 10.1016/0378-8741(86)90074-7.

7. Shinde SD, Hegde RJ. Evaluation of the influence of parental anxiety on children's behaviour and understanding children's dental anxiety after sequential dental visits. Indian J Dent Res 2017;28(1):22-26. DOI: 10.4103/ijdr.IJDR_181_16.

8. Aeschliman SD, Blue MS, Williams KB, et al. A preliminary study on oxygen saturation levels of patients during periodontal surgery with and without oral conscious sedation using diazepam. J Periodontol 2003;74(7):1056-1059. DOI: 10.1902/jop.2003.74.7.1056.

9. Fradelos $\mathrm{E}$, Komini A. The use of essential oils as a complementary treatment for anxiety. Am J Nurs Sci 2015;4(1):1-5.

10. Pradopo S, Sinaredi BR, Januarisca BV. Pandan leaves (Pandanus amaryllifolius) aromatherapy and relaxation music to reduce dental anxiety of pediatric patients. J Int Dent Med Res 2017;10(3):933-937. 